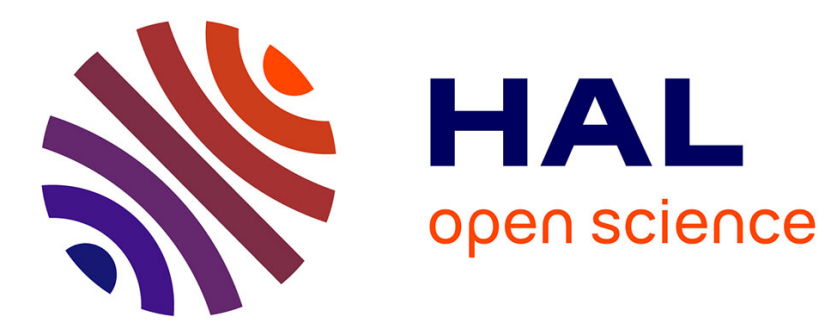

\title{
Structural Relaxation in an Amorphous Rapidly Quenched Cobalt-Based Alloy
}

\author{
V. Fradin, R. Grynszpan, F. Alves, A. Houzali, J. Perron
}

\section{To cite this version:}

V. Fradin, R. Grynszpan, F. Alves, A. Houzali, J. Perron. Structural Relaxation in an Amorphous Rapidly Quenched Cobalt-Based Alloy. Journal de Physique IV Proceedings, 1995, 05 (C1), pp.C1151-C1-156. 10.1051/jp4:1995117 . jpa-00253553

\section{HAL Id: jpa-00253553 https://hal.science/jpa-00253553}

Submitted on 1 Jan 1995

HAL is a multi-disciplinary open access archive for the deposit and dissemination of scientific research documents, whether they are published or not. The documents may come from teaching and research institutions in France or abroad, or from public or private research centers.
L'archive ouverte pluridisciplinaire HAL, est destinée au dépôt et à la diffusion de documents scientifiques de niveau recherche, publiés ou non, émanant des établissements d'enseignement et de recherche français ou étrangers, des laboratoires publics ou privés. 


\title{
Structural Relaxation in an Amorphous Rapidly Quenched Cobalt-Based Alloy
}

\author{
V. Fradin*,**, R.I. Grynszpan*,***, F. Alves**, A. Houzali** and J.C. Perron** \\ * Ecole Nationale Supérieure d'Arts et Métiers, 151 Bd de l'Hôpital, 75013 Paris, France \\ ** Laboratoire de Génie Electrique de Paris, CNRS-URA 0127, Ecole Supérieure d'Electricité, \\ Plateau du Moulon, 91192 Gif-sur-Yvette cedex, France \\ *** Laboratoire Pierre Sue - UMR CNRS 9956, CE-Saclay, 91191 Gif-sur-Yvette cedex, France
}

\begin{abstract}
An amorphous melt-spun Co-based alloy (Metglas $2705 \mathrm{MN}$ ) is investigated by Doppler Broadening and Positron Lifetime techniques in order to follow the microstructural changes yielded by isochronal annealings before crystallization. The results are correlated with those of Differential Scanning Calorimetry and Coercive Field measurements. The quenched empty spaces underlined by Lifetime measurements are less than one atomic volume in size and migrate without clustering in larger voids. Both Positron Annihilation and Coercive Field investigations suggest that the overall decrease of free volume related to structural relaxation in this amorphous material, proceeds mainly via compositional short-range ordering. These local chemical rearrangements which lead to a partial disorientation of the magnetic moments act as strong pinning points for Bloch Walls.
\end{abstract}

\section{INTRODUCTION}

Amorphous Co-based alloys are generally near-zero-magnetostrictive materials. Although their magnetic properties present a low sensitivity to internal stresses, they strongly depend on topological and chemical order, both of which may be affected by thermal treatment [1]. One of the main technological advantages of these alloys, which are used for high-power pulse transformers and tape-head recording applications, arises from the fact that large magnetic anisotropies may be induced by heat treatments at relatively low temperature.

Metallic glasses are metastable solids with no spatially periodic atomic arrangements which on heating relax towards a more stable structure before final crystallization [2]. Since free volume decrease is commonly invoked to explain this structural relaxation process [3-5], several attempts to detect possible related vacancy-like defects have been made using positrons, probes very sensitive to vacancies $[6,7]$. Although it is now accepted that the positron implanted into a metallic glass localizes in regions of lower than average electron density, i.e., positrons exist in a trapped state [8-11], the identification of these traps has not yet been achieved nor is their influence on the properties of metallic glasses well understood.

In this new attempt to tackle the problem of defect identification in amorphous materials, we tried to combine Positron Annihilation investigations with studies using other microstructure sensitive techniques in the hope to obtain a clearer picture of the defect population size and stability.

The present preliminary Doppler Broadening (DB) and Lifetime results obtained on Metglas $2705 \mathrm{MN}$, a melt-spun Co-based amorphous alloy with high saturation induction $\left(B_{s}=1.2 \mathrm{~T}\right)$, high hardness and corrosion resistance, are correlated with both Differential Scanning Calorimetry (DSC) and coercivity results. 


\section{EXPERIMENTAL PROCEDURE}

The melt-spun metallic glass Metglas $2705 \mathrm{MN}\left(\mathrm{Co}_{76} \mathrm{Fe}_{2} \mathrm{Mn}_{4} \mathrm{~B}_{12} \mathrm{Si}_{6}\right)$ was obtained from Allied Chemical Corporation in the form of ribbons $(15 \mu \mathrm{m}$ thick, $25 \mathrm{~mm}$ wide and $2.5 \mathrm{~m}$ long). These rapidly quenched samples underwent isochronal annealings during two hours (heating and cooling rates: $10^{\circ} \mathrm{C} / \mathrm{min}$ ) at temperatures ranging from room temperature to the Curie temperature $\left(407^{\circ} \mathrm{C}\right)$. Changes in the enthalpy which characterize the structural ordering were measured at a heating rate of $40^{\circ} \mathrm{C} / \mathrm{min}$ using a DSC 4 Perkin-Elmer calorimeter [5,12]. Room temperature measurements of the coercive field $\mathrm{H}_{\mathrm{c}}$ were performed at $50 \mathrm{~Hz}$ by applying a sinusoidal induction field of 1 Tesla. Both Doppler Broadening and Lifetime measurements were carried out using two sets of ten discs (10 mm diameter) cut out from the same ribbon and stacked together on each side of the positron source.

This positron source, the same for both DB and Lifetime experiments, consisted of a deposit of $22 \mathrm{NaCl}$ $(0.4 \mathrm{MBq})$ sealed between two $5 \mu \mathrm{m}$ thick Ni foils. DB spectra were acquired with a system comprising an ORTEC HPGe detector (resolution: $1.16 \mathrm{KeV}$ at $511 \mathrm{KeV}$ ) connected to a $16 \mathrm{~K}$ multichannel analyzer (ORTEC Spectrum Master 919). With the as-prepared sample spectrum taken as a reference, we derived the lineshape parameter, $S$, from an energy window $(1.52 \mathrm{KeV})$ centered about the annihilation peak and corresponding to $50 \%$ of the full width of the line at half maximum. In order to detect data smearing due to possible system instabilities, we carried out measurements on a reference specimen after each test of the currently annealed sample. Owing to the very small DB shift observed for the rapidly quenched alloy, particular attention was paid to data reproducibility. In general, repeated measurements on identical samples proved to be reproducible for $\Delta S / S$, within $0.1 \%$, over a period of two months.

Lifetime spectra, acquired with an ORTEC Spectrometer (resolution: 276 psec) were analyzed using a modified version of the POSITRONFIT extended program [13]. After source $\left(\tau_{\text {source }}=374\right.$ psec, $I_{\text {source }}$ $=8.28 \%$ ) and background substraction, the best fits are obtained for a single component analysis.

\section{RESULTS}

Doppler Broadening results present an overall relative change, $|\Delta S / S| \approx 1 \%$ (figure 1). The $S$ parameter seems sensitive to low temperature annealing $\left(100^{\circ} \mathrm{C}\right)$ and reaches a maximum value at about $150^{\circ} \mathrm{C}$ before declining slightly, back to its as-received value at $300^{\circ} \mathrm{C}$. Above that temperature the magnitude of variations in $\mathbf{S}$ becomes more important, suggesting the occurrence of further microstructure modifications. Indeed, $\Delta \mathrm{S} / \mathrm{S}$ presents a sharp drop $(-0.8 \%)$ at $350^{\circ} \mathrm{C}$ followed by an increase at $400^{\circ} \mathrm{C}$. Whereas $\mathrm{DB}$ measurements can be reasonably reproduced for identical samples and annealing up to $300^{\circ} \mathrm{C}$ (within error bars), they seem to be sample dependent above that temperature, i.e.,very sensitive to a possible early crystallization stage taking place in the $350-400^{\circ} \mathrm{C}$ temperature range.

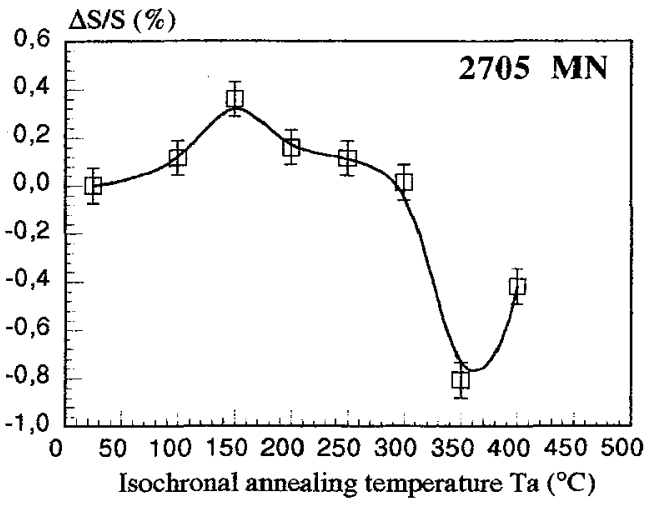

FIGURE 1 - Relative variation of the Doppler broadened lineshape parameter $S$ vs annealing temperature in Metglas (annealing time $\mathrm{t}=2 \mathrm{hrs}$ )

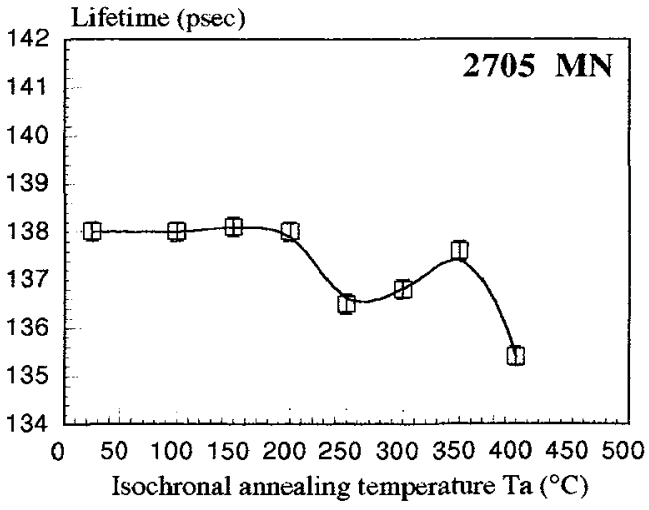

FIGURE 2 - Positron lifetime vs annealing temperature in Metglas 
Positron lifetime and DB measurements were performed on the same samples (figure 2). The lifetime values of the amorphous alloy remain constant after heat treatment between room temperature and $200^{\circ} \mathrm{C}$, whereas $S$ presents a maximum in this temperature range. After these low temperature annealings, $\tau$ reaches a minimum value at $250^{\circ} \mathrm{C}(136 \mathrm{psec})$ before increasing slightly up to $350^{\circ} \mathrm{C}$. Above that temperature, the lifetime decreases again as the crystallization process takes place. The magnitude of changes in $\tau$ between the amorphous and crystalline phases is very weak (less than $3 \mathrm{psec}$ ). Consequently, the lifetime can be considered as quasi-constant during the heat treatment .

The coercive field variation as a function of annealing temperature (figure 3) exhibits one stage before crystallization: $\mathrm{H}_{\mathrm{c}}$ progressively doubles its value as the temperature reaches $200^{\circ} \mathrm{C}$. It tends to decrease slightly with further annealing. Above $300^{\circ} \mathrm{C}$, it exhibits a drastic increase up to a value about one order of magnitude higher than the starting value.

This behavior recalls the evolution of $S$, although to a different extent and with a $50^{\circ} \mathrm{C}$ shift towards higher temperatures. Likewise, except for the sharp drop in $S$ at $350^{\circ} \mathrm{C}$, the increase at $400^{\circ} \mathrm{C}$ of both DB and coercivity parameters seems to indicate that crystallization occurs.

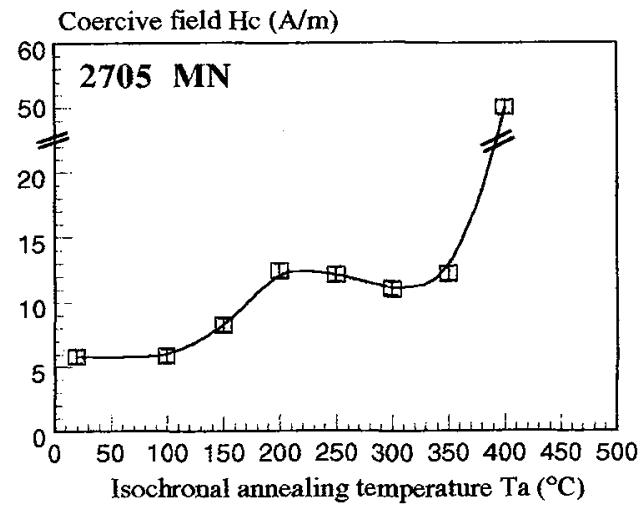

FIGURE 3 - Coercive field $\mathrm{Hc}(\mathrm{f}=50 \mathrm{~Hz}, \mathrm{~B}=1 \mathrm{~T})$ vs annealing temperature in Metglas (annealing time $\mathrm{t}=2 \mathrm{hrs}$ )

Thermograms $\Delta \mathrm{p}$, corresponding to the heat release $\Delta \mathrm{H}_{\mathbf{r}}$ due to relaxation during linear annealing cycles in the DSC calorimeter (figure 4) for as-quenched (aq) and isochronally preannealed samples at various temperatures, $\mathrm{T}_{\mathrm{a}}$, indeed show that crystallization starts slightly below $400^{\circ} \mathrm{C}$.

Let $T_{p}$ be the maximum temperature reached at the end of the first DSC annealing cycle of an as-quenched sample and chosen so as to yield total structural relaxation without crystallization. The baseline described during the second cycle should remain unchanged for any subsequent cycle. If $\Delta \mathrm{p}_{1}\left(\mathrm{~T}_{\mathrm{a}}\right)$ and $\Delta \mathrm{p}_{2}\left(\mathrm{~T}_{\mathrm{a}}\right)$ correspond to the first and second cycles of a preannealed sample respectively, the heat release due to partial relaxation is:

$$
\left.\Delta H_{T(T a}\right)=\int_{T_{0}}^{T_{p}}\left[\Delta p_{2}\left(T_{a}\right)-\Delta p_{1}\left(T_{a}\right)\right] d T
$$

where $\mathrm{T}_{0}$ is the starting temperature of the DSC cycles chosen low enough to prevent any relaxation effect $\left(70^{\circ} \mathrm{C}\right)$. By definition, for the as-quenched sample, (1) yields the heat release due to total relaxation, $\Delta \mathrm{H}_{\mathrm{r}(\mathrm{aq})}$. It is sometimes convenient to define a structural relaxation fraction [14]:

$$
\mathrm{F}_{\mathrm{Sr}}\left(\mathrm{T}_{\mathbf{a}}\right)=1-\Delta \mathrm{H}_{\mathrm{r}}\left(\mathrm{T}_{\mathbf{a}}\right) / \Delta \mathrm{H}_{\mathrm{r}(\mathrm{aq})}
$$

so that, if thermograms remain unchanged during the second cycle, whatever $T_{a}<T_{p}$ :

$$
\mathrm{F}_{\mathrm{Sr}}\left(\mathrm{T}_{\mathrm{a}}\right)=\int_{\mathrm{T}_{0}}^{\mathrm{T}_{\mathrm{p}}}\left[\Delta \mathrm{p}_{1}\left(\mathrm{~T}_{\mathrm{a}}\right)-\Delta \mathrm{p}_{1}(\mathrm{aq})\right] \mathrm{dT} / \int_{\mathrm{T}_{0}}^{\mathrm{T}_{\mathrm{p}}}\left[\Delta \mathrm{p}_{2}(\mathrm{aq})-\Delta \mathrm{p}_{1}(\mathrm{aq})\right] \mathrm{dT}
$$

This seems to be valid for the present isochronal preannealing conditions ( 2 hours) of 2705 MN Metglas [12]. 


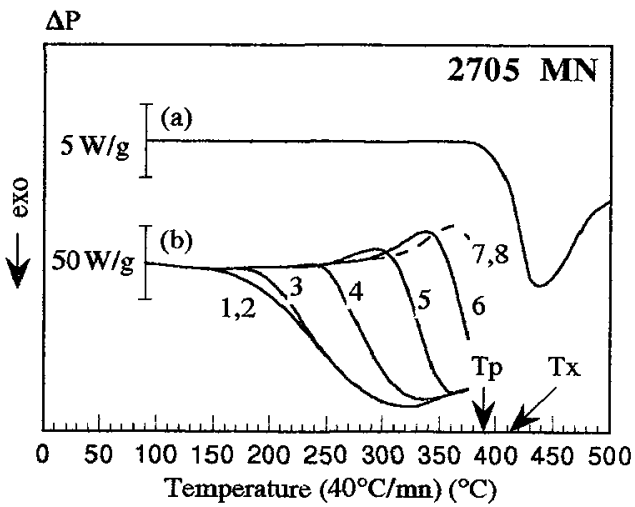

FIGURE 4 - DSC thermograms, $\triangle P$, of the as quenched Metglas until crystallization (a) and up to $\mathrm{Tp}=390^{\circ} \mathrm{C}$ after various isochronal preannealing ( 2 brs) at Ta (b).

1 refers to the as-quenched state and $2,3,4,5,6,7,8$ to $\mathrm{Ta}=100,150,200,250,300,350$ and $390^{\circ} \mathrm{C}$ respectively.

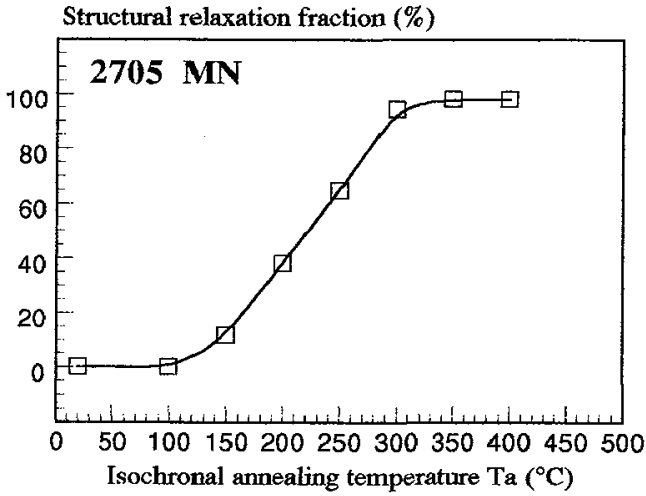

FIGURE 5 - Structural relaxation fraction of Metglas derived from DSC measurements vs preannealing temperature $\mathrm{Ta}$

The temperature dependence of the structural relaxation fraction for this material, derived from determinations of difference curve areas (2) of relevant thermograms, in the temperature range $70-390^{\circ} \mathrm{C}$, is presented in figure 5. Only one stage can be accounted for with a maximum rate occuring at about $220^{\circ} \mathrm{C}$ (for $\mathrm{d}^{2} \mathrm{~F}_{\mathrm{sr}} / \mathrm{dT}_{\mathrm{a}} \mathrm{2}=0$ ), where $\mathrm{H}_{\mathrm{c}}$ seems to be peaking. Above $300^{\circ} \mathrm{C}$, the annealing leads to a relaxed state preceding crystallization.

\section{DISCUSSION}

It is known that lifetime spectra for rapidly quenched materials exhibit only one single lifetime component, i.e., all positrons annihilate from the same state. In these as-received amorphous alloys, positrons are trapped in quenched empty spaces, the so-called Bernal holes [11,15]. The lifetime value of Metglas 2705 MN (138 psec) (figure 2) is longer than the one expected from the lifetime data of pure metallic components (118 psec for $\mathrm{Co}$, main component of the matrix) [16] but shorter than the monovacancy lifetime in transition metals (170-180 psec) [17,18]. Hence, positron annihilation occurs from a definite state between bulk and vacancy, so that the quenched empty spaces explored by positrons are less than one atomic volume in size. Similar facts have been reported for some Fe-based glassy metals [15] where positron trapping takes place more precisely at the largest empty Bernal holes.

For the melt-spun $2705 \mathrm{MN}$ amorphous alloy, in the temperature range up to $300{ }^{\circ} \mathrm{C}$, the Kerr Effect technique [12] shows no significant change in the Weiss domain configuration. On the other hand, DSC analyses suggest that crystallization has not yet started, ruling out a net production of defects (figure 5). Therefore, according to Egami's model [4], the structural relaxation involved in that temperature range could occur at the atomic level via both a topological and a compositional short-range ordering .

According to Kronmüller [19,20], in the case of a non-magnetostrictive material such as the present amorphous Co-based alloy, the main pinning effects contributing to the total coercive field $\mathrm{H}_{c}$ should originate from a clustering process of chemical short-range ordered regions and from relaxation effects due to local structural rearrangements. We may assume that these short-range ordered regions do not act as deep traps for positrons.

As a matter of fact, below $200^{\circ} \mathrm{C}$, the lifetime results exhibit no change, i.e., the empty spaces involved in the positron trapping do not cluster in larger voids. Since our positive field shift $\left(\mathrm{e} . \mathrm{g} .: \mathrm{H}_{\mathrm{c}, 200}{ }^{\circ} \mathrm{C}-\mathrm{H}_{\mathrm{c}, \mathrm{RT}}=\right.$ $6 \mathrm{~A} / \mathrm{m}$ ) (figure 3) cannot result from an increase in the density of vacancy-like defects, it should be related to an enhancement of the density of Bloch Wall pinning points or to the improvement of their pinning efficiency. Indeed, a rise in the Doppler Broadening lineshape $S$ is observed (figure 1) indicating an enhancement of the annihilation rate with low momentum electrons. This positive $\Delta S / S$ change may be due 
to a modification of the positron chemical environment. The relative positions of the energy levels of delocalized positrons between different components in contact are determined by the positron affinity which is a specific bulk property of each material [21]. Nevertheless, the influence of the chemical environment on the S parameter remains difficult to estimate. The migration of the empty spaces could also release local stresses and induce short-range ordering without clustering in voids large enough to yield a second visible lifetime component. These local chemical rearrangements which lead to a partial disorientation of the magnetic moments may induce strong Bloch Wall pinning effects and result in the sharp rise observed for $\mathrm{H}_{\mathrm{c}}$ is in this temperature range.

As the thermal treatment proceeds from 200 to $300^{\circ} \mathrm{C}$, the lifetime which remains constant within less than $2 \mathrm{psec}$ appears rather insensitive to the structural relaxation. Since the positron trapping efficiency decreases as indicated by the decline of $S$ in this temperature range (figure 1 ), the coercive field should be lowered. The rather slight decrease in $\mathrm{H}_{\mathrm{c}}$ suggests that, whereas the overall number of pinning points decreases, the chemical rearrangements are significant enough to keep $\mathrm{H}_{\mathrm{c}}$ at a high value $(12 \mathrm{~A} / \mathrm{m})$. This relaxation stage associated with the disappearance of the free volume excess, could lead to a more uniform amorphous structure.

Above $300^{\circ} \mathrm{C}$, crystallization starts to prevail as indicated by the structural relaxation fraction $F_{\mathbf{s r}}$ derived from DSC measurements. In this temperature range, a huge increase in $\mathrm{H}_{\mathrm{c}}$ is observed (up to about $40 \mathrm{~A} / \mathrm{m}$ between 350 and $400^{\circ} \mathrm{C}$ ) corresponding to a negative relative change in $S$ (about $0.8 \%$ ) followed by a new increase of this parameter. It is inferred that crystallization, completed around $412{ }^{\circ} \mathrm{C}$ for $2705 \mathrm{MN}$, is accompanied first by an atomic rearrangement that leads to a total free volume decrease and then, proceeds with the formation of new extended defects such as precipitates which will favor Bloch Wall pinning and lead to an increase of the S parameter. Indeed, such a positive shift in S, associated with possible precipitation-induced defects (pseudo-dislocations, debris...) has already been reported [22]. The crystallization induces a slight decrease of the lifetime value $(135 \mathrm{psec})$, generally observed for melt-spun alloys [23], indicating that positron trapping still occurs.

The structural relaxation process in this present rapidly quenched alloy does not occur uniformally throughout the full annealing temperature range, in contrast to the single stage evolution of the structural relaxation fraction. Although $\Delta \mathbf{S} / \mathbf{S}$ changes still remain difficult to explain, this process seems to proceed in several steps involving local compositional rearrangements and annealing.

\section{CONCLUSION}

Lifetime measurements performed on Metglas $2705 \mathrm{MN}$ have confirmed the existence of only one type of positron trap but seem insensitive to the structural relaxation state as generally observed for melt-spun alloys. By annealing, these shallow traps consisting of quenched empty spaces, less than one atomic volume in size, migrate without clustering in larger voids.

In this melt-spun alloy, the observed coercive field changes are essentially due to an increase of either the density or the efficiency of the Bloch Wall pinning points. These pinning points are most likely related to a release of local stresses and to a compositional short range ordering induced by the migration of the quenched empty cavities. Indeed, the partial disorientation of the magnetic moments due to such local chemical rearrangements causes them to act as strong pinning points for Bloch Walls. Hence, structural relaxation appears as an inhomogeneous process mainly controlled by compositional short-range order.

\section{REFERENCES}

[1] Gibbs M., Evetts J. and Leake J., J. Mater. Sci 18 (1983) 278-288

[2] Ravindrachary V., Sreepad H., Chandrashekara A., Ranganathaiah C. and Gopal S., Mater. Sci. Forums 105-110 (1992) 1201-1204

[3] Egami T., J. Mater. Sci. 13 (1978) 2587-2599

[4] Egami T., Mater. Res. Bull. 13 (1978) 557-562

[5] Harmelin M., Etchessahar E., Debuigne J. and Bigot J., Thermochimica Acta 130 (1988) 177-192

[6] Hautojärvi P., Hyperfine Int. 15/16 (1983) 357-370

[7] Smedskjaer L.C. and Fluss M.J., Methods of Experimental Physics 21, ed. Mundy J.N., Rothman S.J., Fluss M.J. and Smedskjaer L.C., (Academic Press Inc., 1983) pp.77 
[8] Shiotani N., Proc. 6th ICPA, Positron Annihilation, ed. Coleman P., Sharma S., Diana L., (North Holland Publ. Co., Amsterdam, 1982) pp. 561-572

[9] Hautojärvi P. and Yli-Kauppila J., Nuclear Instr.and Methods 199 (1982) 75-86

[10] Kajcsos Z., Kemeny T. and Brauer G., Nuclear Inst. and Methods 199 (1982) 373-382

[11] Triftshaüser W. and Kögel G., Amorphous and Liquid Materials, ed. Lüscher E., Fritsch G. and Jaccuci G., (Martinus Nijhoff Publ., 1987) pp. 218

[12] Alves F., Doctorat Thesis, Université de Paris Sud, Orsay (1993)

[13] Virtue C., Douglas R. and McKee B.T.A., Comp. Phys. Comm. 15 (1978) 97-105

[14] Escobar Valderrama M.A., Doctorat Thesis, Institut National Polytechnique de Grenoble (1991)

[15] Kögel G., Liquid and Amorphous Metals, ed. Lüscher E., and Coufal H., (Sijthoff \& Noordhoff, 1980) pp. 661

[16] Dannefaer S. and Kerr D., Can. J. Physics 58 (1980) 270-280

[17] Moser P., Corbel C., Proc. Int. School of Physics "Enrico Fermi", Positron Solid State Physics, ed. Brandt W. and Dupasquier A., (North Holland Publ. Co., Amsterdam, 1983) pp. 682

[18] Dlubek G., Brümmer O., Meyendorf N., Hautojärvi P., Vehanen A. and Yli-Kauppila J., J. Phys. F 9 (1979) 1961-1973

[19] Kronmüller H., J. Magnetism Magn. Mater. 24 (1981) 159-167

[20] Kronmüller H., J. Appl. Phys. 52 (1981) 1859-1864

[21] Hunter D., Doctorat Thesis, Ecole Nationale Supérieure d'Arts et Metiers, Paris (1993)

[22] Borrell M., Grynszpan R.I. and Ji N., Mater. Sci. Forums 105-110 (1992) 909-912

[23] Moser P., Hautojärvi P., Yli-Kauppila J. and Corbel C., Rad. Effects 62 (1982) 153-160 